\title{
Developmental expression patterns of Bcl-2, Bcl-x, Bax, and Bak in Teeth
}

Stanislaw Krajewski ${ }^{1,4}$, Alfons Hugger ${ }^{2}$, Maryla Krajewska ${ }^{1}$, John C. Reed ${ }^{1}$ and Jürgen K. Mai ${ }^{3}$

1 The Burnham Institute* (formerly La Jolla Cancer Research Foundation), 10901 North Torrey Pines Road, La Jolla, CA 92037, USA

2 Westdeutsche Kieferklinik, Heinrich-Heine-Universität Düsseldorf, PO Box 10 10 07, 40001 Düsseldorf, Germany

${ }^{3}$ Institut für Neuroanatomie, Heinrich-Heine-Universität Düsseldorf, PO Box 10 10 07, 40001 Düsseldorf, Germany

4 corresponding author: Dr. S. Krajewski. tel: (619) 455-6480; fax: (619) 6463196; email: stan@ljcrf.edu

Received 28.8.97; accepted 28.11.97

Edited by D. Green

\begin{abstract}
The ontogenic profile of expression of four members of the $\mathrm{Bcl}-2$ family (Bcl-2, Bcl-x, Bax and Bak) was examined in the mouse by immunohistochemistry using paraffin sections. All four members were expressed in changing patterns during critical stages of tooth morphogenesis. Expression was detected in epithelial cell populations including the dental lamina, internal dental epithelium (IDE; differentiating ameloblasts), stratum intermedium and stellate reticulum cells, as well as in the condensed dental mesenchyme. The temporospatial localization of the various members of the Bcl-2 family in dental epithelium and mesenchyme showed striking overlapping areas but often their expression patterns differed. In general, contemporaneous co-expression of the Bcl-2 and Bax proteins, and of the $\mathrm{Bcl}-\mathrm{x}$ and Bak proteins was noted in various types of cells during the developmental process, with the intensity of Bcl-2 $>$ Bax and of Bak $>\mathrm{Bcl}-\mathrm{x}$. Expression was pronounced at sites where interaction between surface ectoderm and induced mesenchyme takes place, and at the enamel knot, which is regarded as organization/regulating center for tooth development. Around birth, after the structural maturation was accomplished, the expression was downregulated. The absence of elevated expression of each of these four members of the Bcl-2 family after birth in the teeth suggests that these proteins are relevant during the accomplishment of the basic architecture but not once the structure of the tooth is established.
\end{abstract}

Keywords: murine development; teeth; $\mathrm{Bcl}-2$ protein family expression

Abbreviations: $\mathrm{BM}$, basal membrane; $\mathrm{DAB}$, diaminobenzidine; $\mathrm{DePa}$, dental papilla; E11, E15.5, embryonal day 11, 15.5; EDE, external dental epithelium; IDE, internal dental epithelium; IR, immunoreactivity; IEL, inner enamel layer (inner dental epithelium); $\alpha$ FGF and $\beta$ FGF, $\alpha$ and $\beta$ fibroblastic growth factors; IGF-1, Insulinlike growth factor-1; Mes, mesenchyme; Od, odontoblasts; P4, postnatal day 4; PAB, polyclonal antibodies; PBS, phosphate buffered saline; PFA, paraformaldehyde; SG/VIP immunocytochemical colorimetric substrates; StR, stellate reticulum; Strl, stratum intermedium; TdT, terminal deoxynucleotidyl transferase; Tunel, terminal deoxynucletidyl transferase (TdT)-mediated dUTPdigoxenin $3^{\prime} \mathrm{OH}$ end-labeling; Z-Fix, zinc buffered formalin

\section{Introduction}

Tooth development proceeds in a well established sequential cascade of events beginning in the oral ectodermally-derived odontogenic placode through bud, cap and bell stages and culminating in the formation of the mineralized enamel extracellular matrix. Corresponding regulatory processes of tooth formation are being disclosed by the correlation with tooth development of the expression patterns of various genes, such as cell and substrate adhesion molecules of the mesenchymal extracellular matrix (Thesleff et al, 1991), carbohydrate residues (Lemus et al, 1996), growth factors and their receptors including IGF-I receptor, neurotrophins, and both $\alpha \mathrm{FGF}$ and $\beta \mathrm{FGF}$ (Joseph et al, 1994; Mitsiadis et al, 1992, 1993; Mitsiadis and Luukko, 1995; Thesleff et al, 1995b), among others (Cam et al, 1992; Thesleff, 1995a; Thesleff et al, 1995c; Tureckova et al, 1995).

This sequential developmental cascade of events is accompanied by programmed cell death (apoptosis). Approximately $50 \%$ of the ameloblasts die during enamel maturation (in the post-secretory transition and maturation ameloblasts) (Joseph et al, 1994). By using the TUNEL method, additional loci of cell death have been identified, including the central cells of the invaginating dental epithelium, later (during cusp development) in the enamel knots, and in other epithelial cell populations including the dental lamina, ameloblasts, as well as stratum intermedium and stellate reticulum (Vaahtokari et al, 1996b). Detection of proliferating cells in the tooth germ revealed a nearly complete lack of co-localization with apoptosis [almost segretated locations of apoptosis and proliferation] (Vaahtokar et al, 1996a, 1996b). These data support the view that withdrawal from the cell cycle is a temporal prerequisite for undergoing apoptosis. Analysis of proteins of the Bcl-2 family, which are important regulators of cell death during sequential stages of tooth development provides the opportunity to investigate their role during morphogenesis, cytodifferentiation, and spatial organization. In this study the localization of various members of the Bcl-2 family during critical stages of tooth morphogenesis in the mouse was investigated, providing evidence for topographically restricted transient expression patterns of these proteins. Though speculative, the localization of 
these molecules may help to explain some of the features of congenital malformation syndromes.

\section{Results}

Each of the four members of the Bcl-2 family was expressed at least for some period simultaneously and at a comparable developmental stage in the transient dental primordia.

\section{Dental lamina (E11)}

At day 11 of mouse development, when the oral epithelium shows localized thickening and the first signs of cell in-growth into the underlying mesenchyme, these areas became positive for Bcl-2 and Bak (not shown).

\section{Bud-stage (from E13)}

During the bud-stage $\mathrm{Bcl}-2$ was present as granular deposits in the cytoplasmic compartments of the cells in the condensed mesenchyme directly underlying the in-grown epithelium (not shown). In addition few scattered highly positive cells appeared in the periphery of the dental follicle, between the compacted and loose mesenchyme. Bak-positive cells were also found in this location. There was still no noticeable immunoreactivity (IR) for Bcl-x and Bax at this stage.
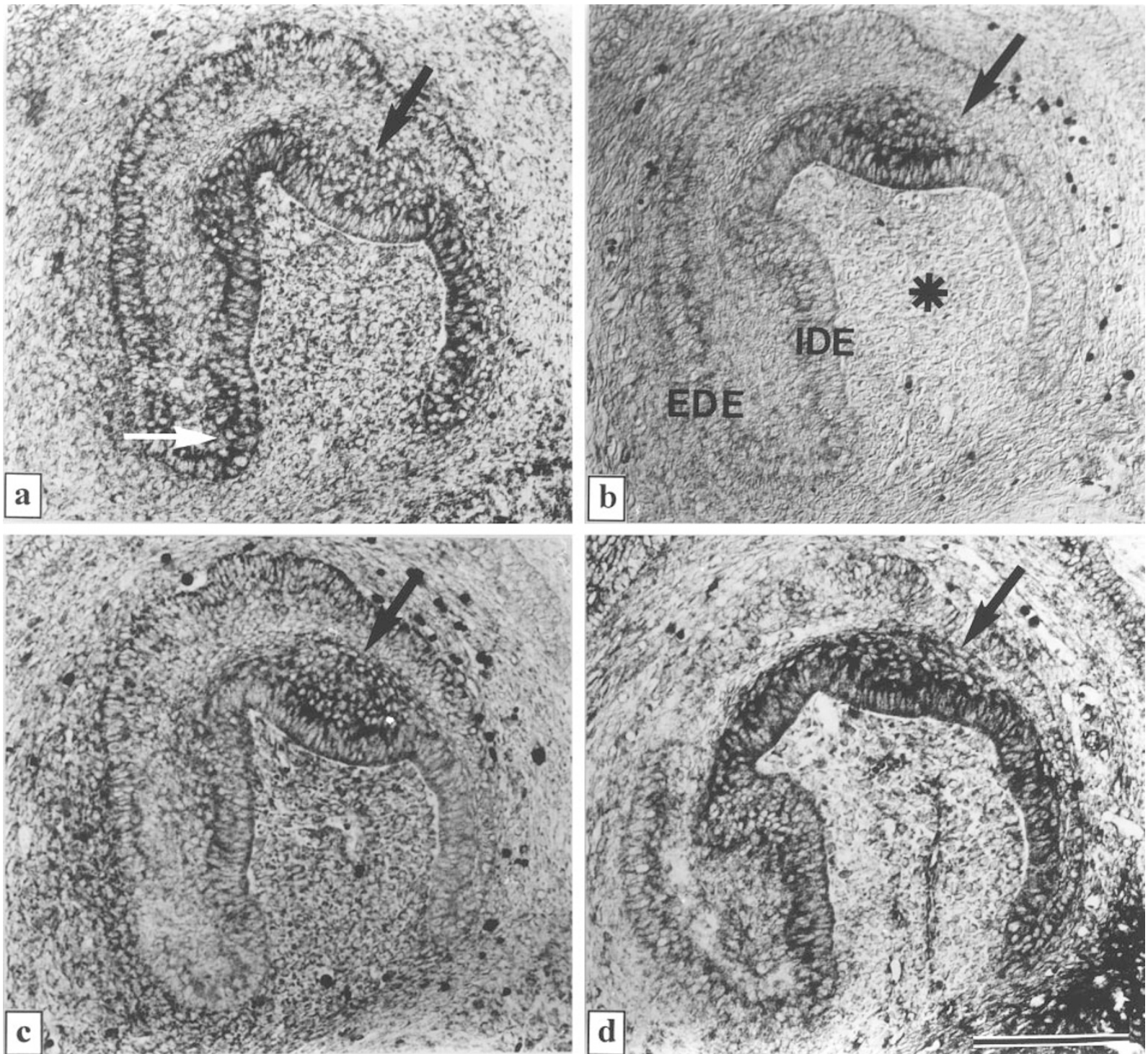

Figure 1 Expression of $\mathrm{Bcl}-2(\mathbf{a}), \mathrm{Bcl}-\mathrm{x}(\mathbf{b}), \mathrm{Bax}(\mathbf{c})$, and Bak (d) during late cap-stage (E14.5). The Bcl-2 staining is confined to granular or vesicular structures within the cytoplasm. It is localized predominantly in the internal dental epithelium (IDE) and at the rim of the dental organ (junctional zone or cervical loop, white arrow). To a lesser extent $\mathrm{Bcl}-2$ is present in the cytoplasm of the external dental epithelial cells (EDE) and in mesenchymal cells of the dental papilla, whereas Bcl$\mathrm{x}$ immunostaining was not present in these cells (b; asterisk). Bcl-x (b) and Bax (c) are prominent in the forming enamel knot (black arrows), particularly where the cells of the enamel knot abut the IDE. Bcl-x is also elevated at the mesenchymal-epithelial junction of the EDE. Both proteins are almost absent from the cervical loop. Bak is prominent in the enamel knot and it is located in the cells of the IDE with preference of the cellular portion adjoining the stratum intermedium. Cells of the stratum intermedium are moderately positive. Bak IR is almost absent in the EDE. All sections show only reaction product without counterstain. Scale bar represents $100 \mu \mathrm{m}$ 

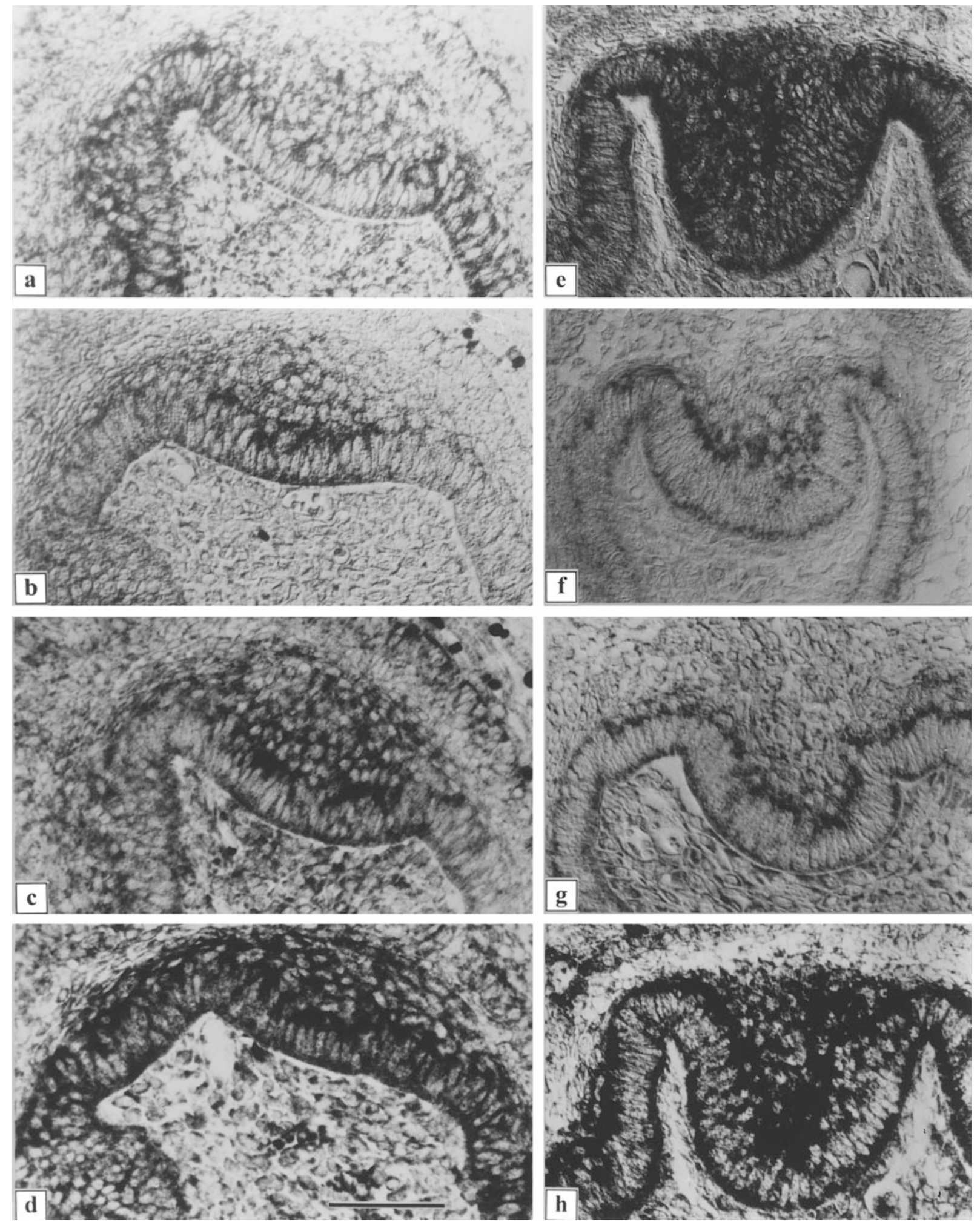

Figure 2 The area of the enamel knot during the late cap (E14.5, a-d, higher magnification of the series shown in Figure 1) and bell (E15.5, e-h) stages. At E14.5 the highest contrast between the enamel knot and neighboring structures is found in sections stained for Bcl-x and Bax (b, c). IR at E15.5 shows decreased levels of Bcl-x (f) and Bax (g) expression in this area and the immune product becomes concentrated at the 'border' between the enamel knot and the IDE. From $\mathrm{E} 14.5$ (a, d) to E15.5 (e, h) IR for Bcl-2 and Bak has increased considerably. Bcl-2 is evenly distributed in the center of the enamel knot (e), whereas Bak is found in higher concentration at the periphery of IDE cells $(\mathbf{h})$. Scale bar represents $50 \mu \mathrm{m}$ 


\section{Cap-stage (E14.5)}

From the time when the internal dental epithelium (IDE) forms a layer of single cells, the expression of the four members of the Bcl-2 family became intensified. The distribution of IR showed substantial differences (Figure 1). Bcl-2 was present in the IDE $(2-3+)$ and the external dental epithelium (EDE; 1-2+), with increased intensity at the rim of the dental organ (junctional zone or cervical loop, 2-3+; Figure 1a, white arrow), and in mesenchymal cells of the dental papilla (1+, Figures 1a and 2a). Bcl-x and Bax were present mostly in the forming enamel knot and IR was particularly prominent where the cells of the enamel knot about the IDE (2-3+, Figure 1b,c; black arrows, Figure $2 b, c$. Both proteins were essentially absent from the cervical loop $(0-1+$, Figure $1 b, c)$, an area of high $\mathrm{Bcl}-2$ expression. Bcl-x expresion in the dental papilla (Figure $1 \mathrm{~b}$, asterisk) and EDE was substantially lower than Bcl-2, Bax and Bak (0-1+versus 2+). Bak IR was prominent in the enamel knot
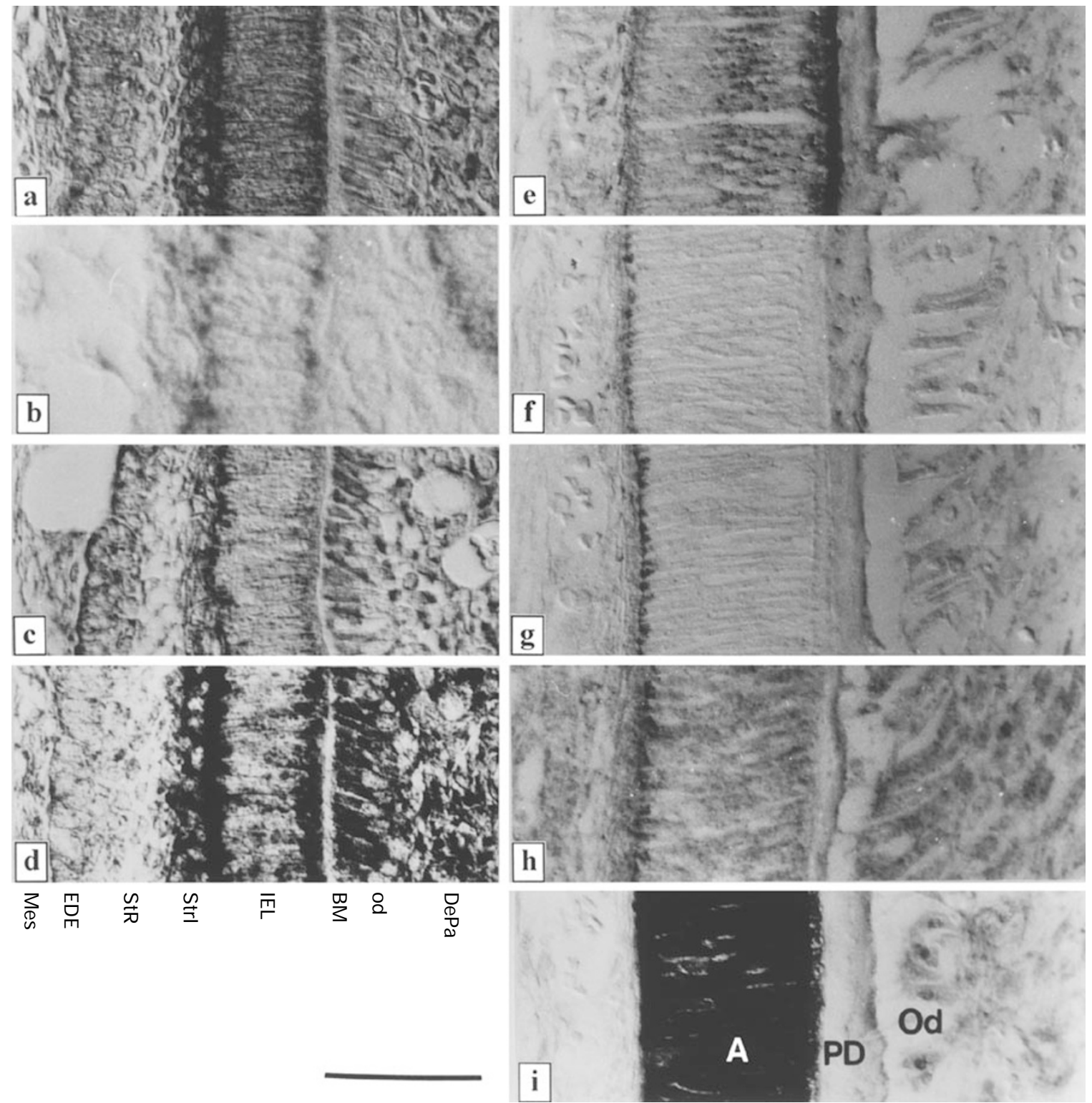

Figure 3 Localization of $\mathrm{Bcl}-2(\mathbf{a}, \mathbf{e}), \mathrm{Bcl}-\mathrm{x}(\mathbf{b}, \mathbf{f}), \operatorname{Bax}(\mathbf{c}, \mathbf{g})$, and Bak (d, h) dfuring the early bell stage (E15.5, a-d) and the late bell stage (E19, e-h). Segments of tissue through the IDE stained for the different proteins. At E15.5 the Bcl-2 positive cells of the are polarized: they contain coarse positive granules at their extremes. Bcl-2 occurs at the basal and apical poles and in the perinucleate region of the IDE cells. Bcl-x and Bax are expressed especially at the basal cell parts alone (b, c); Bak is found at high intensities in the basal and apical poles of the IDE cells and some granular material is located at the intercellular membranes between the IDE cells (d). Around birth (E19, e-h), IR for all four members of the Bcl-2 family is found at low levels in the basal terminal web of the ameloblasts. $\mathrm{Bcl}-2$ differs as it is additionally expressed, in high concentration, at the secretory pole of ameloblasts (within the enamel-predentin area) and also in the perinuclear region (e). (i) neighboring section showing calbindin IR of the ameloblasts. (Abbreviations: A: ameloblast layer, BM: basal membrane, DePa: dental papilla, EDE: external dental epithelium, IEL: inner enamel layer, IDE: inner dental epithelium, Mes: mesenchyme, Od: odontoblasts, PD: predentin, StR: stellate reticulum, Strl: stratum intermedium, scale bar: $50 \mu \mathrm{m}$ ) 
$(3+$, Figures $1 d, 2 d)$ and it was located in the cells of the IDE with preference for the cellular portion adjoining the stratum intermedium. Cells of the stratum intermedium were moderately Bak positive, whereas Bak IR (like $\mathrm{Bcl}-\mathrm{x}$ ) was almost absent from the EDE at this stage (Figure $1 a-d$ ). Though exception existed, in general, Bcl-2 and Bax expression followed the same temperospatial pattern while $\mathrm{Bcl}-\mathrm{x}$ and Bak expression occurred contemporaneously. However, typically the intensity of $\mathrm{Bcl}-2$ immunostaining was usually greater than Bax, while Bak was often greater than Bcl-x.

\section{Bell-stage}

$\mathrm{Bcl}-2 \mathrm{IR}$ became greatly reduced in the IDE along the cervical loop; however, a small segment and the medially neighboring area, representing the proliferation zone for the mesenchymal cells of the dental papilla (Casasco et al, 1992; Sicher and Bhaskar, 1972), exhibited numerous positive cells at this time. Some of these showed highly immunoreactive coarse granules in their cytoplasm (not shown). IR for Bcl-x and
Bax, which was present during the cap stage within the enamel knot, was at this stage downregulated in these cells, but concentrated along the basal part of the IDE against and around (lateral to) the enamel knot thus indicating a borderline between these compartments which is not visible in regularly stained specimens (Figure 2f,g). Bcl-2 and Bak, which gave only a moderate signal at the enamel knot during the cap stage (1-2+, Figure 2a,d), now exhibited increased immunostaining intensity in the cells of the enamel knot $(3+$, Figure $2 e, h)$. During the early bell-stage (E15-16) generally the intensity of IR in the polarized basal and particularly at the apical cell regions that were in contact with basal membrane (BM; Figure $3 \mathrm{a}-\mathrm{d}$. Bcl-2 and Bak were at their highest expression level, especially in the stratum intermedium, adjacent to BM (3+, Strl; Figure 3e,h). During this stage, odontoblasts were positive for Bak and to a much lesser degree also for Bax and Bcl-2, whereas Bcl-x was absent. IR was localized in the apical portion of their cytoplasm. The gradient of $\mathrm{Bcl}-2$ and Bak expression in IDE decreased towards the cervical loop, similar to that observed previously
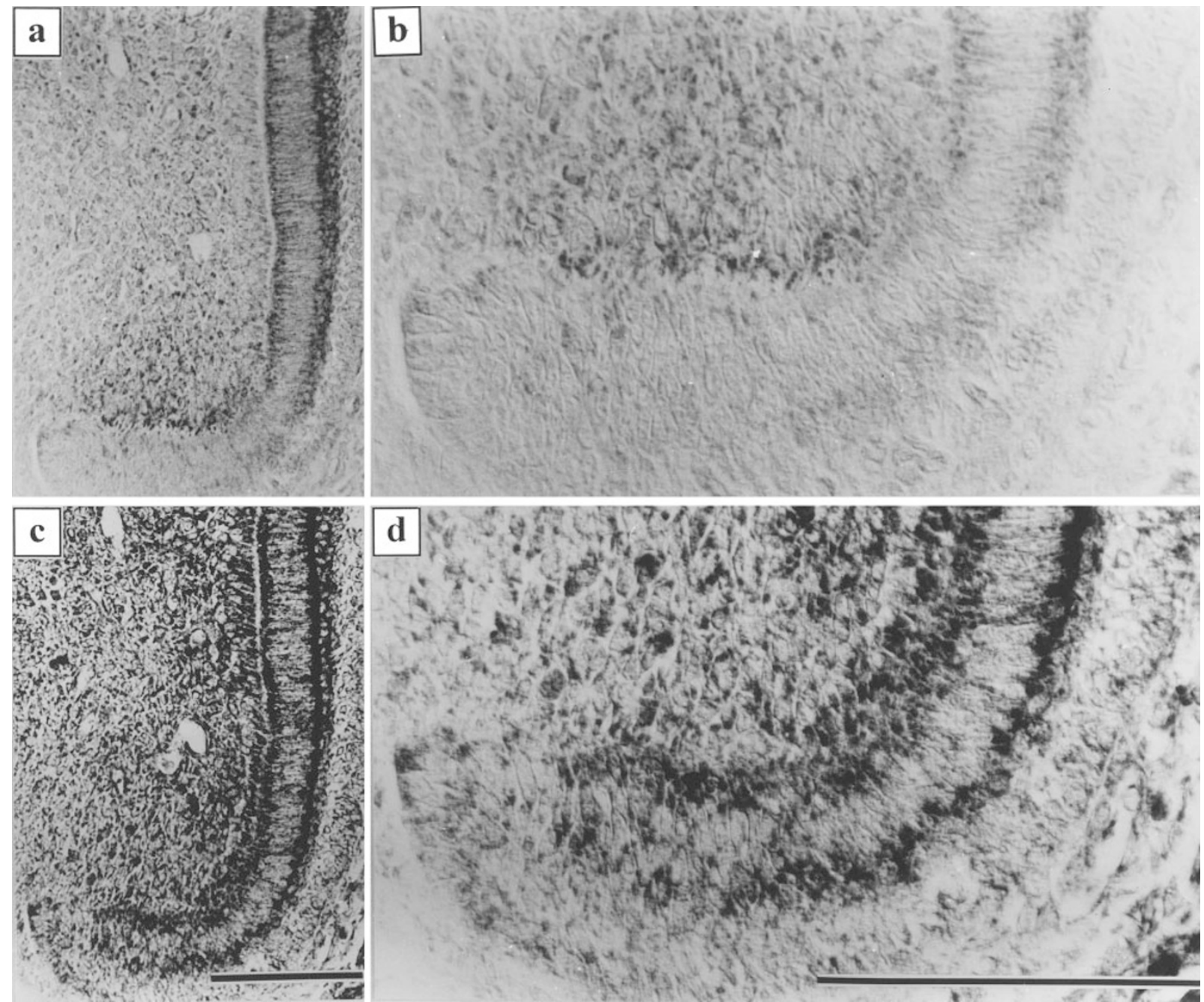

Figure 4 Localization of Bcl-2 (a,b) and Bak (c, d) during the early bell stage (E15.5). Note the decreasing gradient of immunostaining at the cervical loop for both markers and scattered positive mesenchymal cells of the dental papilla (Scale bars: $100 \mu \mathrm{m}$ ) 
for Bcl-x and Bax in the cup and early bell stages (Figure 1a, $\mathrm{d}$, and Figure $4 \mathrm{a}-\mathrm{d}$ ).

\section{Around birth (E19)}

IR in the teeth was low but principally found in the same location among the ameloblasts as during the early bell stage (compare Figure $3 a-d$ with Figure $3 e, h$ ). The four members of the Bcl-2 family were always expressed in the proximal (basal) portion, which represents the proximal terminal web complex. Bcl-2 was additionally found at the secretory pole in the distal (apical) terminal web complex and was also present in the middle third of the ameloblast layer during the early bell stage (Figure $3 e$ ). Odontoblasts contained fine granules of very low IR for Bcl-2 and Bak in the apical portion of the cells. These granular deposits gradually decreased as the ameloblasts made the transition towards enamel maturation (Figure $3 e-h$ ).

\section{Postnatal period}

After birth, the level of IR was even more reduced and only traces of immune reactions for all proteins were detectable in the ameloblast layer.

\section{DNA Fragmentation Assay (TUNEL)}

The results of TUNEL analysis revealed similar pattern of positive nuclei (fragmented DNA) as that described recently by Vaahtokari et al. (1996a). These TUNEL-positive nuclei were mostly found among the condensed mesenchymal cells, invaginating dental epithelium during formation of enamel knot or in the dental papilla, cells in stellate reticulum and scattered ameloblast in IDE (not shown). Some of these TUNEL-positive cells were also strongly positive for Bak. There was no obvious colocalization of other Bcl-2 family proteins with TUNEL positivity.

\section{Discussion}

\section{Regional expression at sites of epithelium - mesenchymal interactions}

Development of the teeth is characterized by the in-growth of induced ectoderm into the mesoderm, which is derived from neural crest cells of the isthmus region, and subsequent reciprocal interactions between the cells located at the epithelial-mesenchymal interface. It is well known that the dental epithelium (inner dental epithelium; IDE) and dental mesenchyme play important roles in morphogenesis and inductive tissue interactions (Saxen and Thesleff, 1992; Thesleff et al, 1991, 1995b). We have shown that in those areas, where such interactions occur, the four members of the $\mathrm{Bcl}-2$ family are transiently expressed. They are not equally expressed during the prenatal period (during morphogenesis and cytodifferentiation); instead clear evidence of compartmental expression patterns was noted. It might therefore be speculated that special combinations of $\mathrm{Bcl}-2$ family are active during the patterning/sculpturing of the teeth. Differences between Bcl-2 and Bak on one hand, and $\mathrm{BCl}-\mathrm{x}$ and $\mathrm{Bax}$ on the other hand, were particularly prominent. From E12 and throughout the stages of bud and cup formation, Bcl-2 and Bak were expressed in the subjacent stretch of condensed mesenchyme, corresponding to the leading pole of invagination, when the dental lamina thickens. By E14.5, during the late cup and beginning bell stages, the IDE becomes Bcl-2 and Bak immunopositive with accentuation at the dentino-enamel junction. Typical for Bak is the finding that the oral epithelium, which invaginates and undergoes continuous remodeling, stays positive for Bak. (Before odontoblasts were identified, Bcl-2 was predominantly expressed in the mesenchyme; later it was concentrated in the ameloblasts layer in a location where Bak IR was also present). Bcl-x and Bax were first observed rather late during tooth development, in the cup stage. Moreover, the expression appeared rather localized to the central area of the IDE, at a place topographically fitting to the primary enamel knot (Vaahtokari et al, 1996b). The IR of $\mathrm{Bcl}-\mathrm{x}$ and $\mathrm{Bax}$ at this position increased during the prenatal time, whereas the IR of the mesenchyme was extremely weak.

Around the time of birth and shortly thereafter, the IR in the ameloblasts was located in the terminal web complex where actin processes are found. This location adds to many other, which are also characterized by actin processes, like the smooth and striated muscle fibers, myoepithelial cells and outer hair cells. Bcl-2 and Bak are additionally found in the distal (apical) terminal web complex and in the Tomes-processes, where calcium ions become deposited.

\section{Regional expression at the putative organizing center of tooth development, the enamel knot}

There is increased evidence that the enamel knot serves as an organization center for teeth development (Thesleff et al, $1991 ; 1995 b)$ comparable to the anterior epithelial ridge and posterior necrotic zone (Saunders, 1966). The finding that members of the Bcl-2 family are expressed in this putative center suggests a role in organizing tooth morphogenesis. It is interesting to note, that during cap stage the expression of $\mathrm{Bcl}-\mathrm{x}$ and Bax appears prior to $\mathrm{Bcl}-2$ and Bak, and that the location of these groups with respect to the enamel knot differs. This suggests specialized roles for particular members of the Bcl-2 family in tooth development.

\section{The relationship between ameloblast cytology, terminal differentiation, apoptosis and $\mathrm{Bcl}-2$ protein family expression}

The process of apoptosis is best analyzed for the ameloblasts. Because the development of the murine incisors is a continuous process, all stages of ameloblast differentiation can be analyzed at one time in this location. Before secretion of the enamel matrix begins, preameloblasts become post-mitotic. They then undergo a remarkable transition from a protein secreting cell to one active in enamel matrix maturation. This transition is accompanied by apoptosis or programmed cell death of approximately $25 \%$ of the ameloblasts. An additional $25 \%$ of ameloblasts 
undergo apoptosis when maturation of enamel matrix takes place with removal of water and protein from the increasingly mineralized matrix (Mitsiadis et al, 1993; Nishikawa and Sasaki, 1995). Interestingly, the expression of both, Bcl-2 and $\mathrm{Bxl}-\mathrm{x}_{(\mathrm{L})}$, which inhibit cell death, is largely reduced before the transition into the maturationstage ameloblasts occurs and before apoptosis and DNA degradation in ameloblasts is induced (Nishikawa, 1995). Moreover, during the phase of transition, no change in the expression of any of the four members of the Bcl-2 family was noticed. The role of expression of $\mathrm{Bcl}-2, \mathrm{Bcl}-\mathrm{X}, \mathrm{Bax}$, and Bak in this cell type therefore might not be related to actual cell death, but possibly to balancing cell life and death signals during cell differentiation. It is conceivable that the protein levels are changed in pathological conditions where elimination of 'defective' ameloblasts results in abnormal enamel production.

\section{Transient $\mathrm{Bcl}-2$ family expression versus continuity of tooth development}

As discussed above, the development of the incisors in the mouse is a continuous process. All morphological events [which we could correlate with the elevated levels of peptide expression] during the late prenatal period (bell stage), continue throughout life. Expression of Bcl-2 family proteins, however, was down-regulated once the structural maturation was accomplished. The absence of significant expression of any of these $\mathrm{Bcl}-2$ family proteins after birth suggests that these proteins are relevant during the accomplishment of developmental programs (during development of the basic architecture) but not for the subsequent maintenance of teeth. Though we cannot exclude the possibility of expression of other $\mathrm{Bcl}-2$ family proteins not examined in this study, the data nevertheless imply that once the morphogenesis of teeth is completed, there exists less need for proteins such as Bcl-2, $\mathrm{Bcl}-\mathrm{x}$, Bax, and $\mathrm{Bak}$, which regulate the process of programmed cell death.

\section{Materials and Methods}

\section{Animals}

The timing and the distribution of the expression of several members of the BCL-2 family was assessed in paraffin sections derived from embryos and from postnatal mice. Prenatal development was studied on a closely spaced series of mouse embryos at daily intervals from 4 days of gestation (E4) to E8 and half-day intervals from E8 until postnatal day 4 (P4). 32 mice were studied at regular intervals after that time until adulthood. Mice were mated overnight, and the morning when the vaginal plug appeared, was designated as embryonal day 0.5 (E0.5). The day of birth was termed as postnatal day zero (P0). All embryos were taken from mice that had been killed by either overdose of ether or carbon monoxide. At E4-9, the uterus was excised and fixed with the embryos in situ. For the later embryos, each embryo was dissected out from the uterus, freed from the extraembryonic membranes and immediately placed in the fixative. Staging of embryos was additionally performed on the basis of external measurements (crown rump length), external morphology and the advent of organ development.

\section{Methods}

Embryos and postnatal animals were fixed in either phosphate buffered $4 \%$ paraformaldehyde (PFA), Bouin's solution (Sigma Inc. St. Louis, USA), or zinc buffered formalin (Z-Fix; Anatech LTD, Battle Creek, MI, USA). Fixed embryos were washed in phosphate buffered saline (PBS), followed by dehydration through a series of ethanols in PBS, embedded in paraffin and sectioned (thickness either 5 or $20 \mathrm{~mm}$ ) according to standard procedures.

\section{Immunohistochemistry}

Dewaxed sections of whole mouse embryos were exposed to polyclonal antibodies ( $\mathrm{PAB}$, generated against synthetic peptides) specific to Bcl-2, Bcl-X, Bax, and Bak. For detection of Bcl-2 two PAB's were used: 1632 and 1634 . They were either applied separately or were mixed in equal amounts. The preparation and characterization of antibodies with specificity for mouse Bcl-2, Bax, Bcl-X and Bak have been described previously (Krajewska et al, 1996; Krajewski et al, $1994 a, 1994 b, 1995,1996)$. Visualization of the location of the antibodies was by the PAP or ABC technique as described elsewhere (Krajewski et al, 1994a, 1994b, 1995; Sicher and Bhaskar, 1972). The immunoreactivity (IR) results were scored with respect to relative intensity on a 4-point scale as: no detectable staining (0), weak (1+), moderate $(2+)$ and strong $(3+)$. On selected representative sections the detection of nuclei with fragmented DNA (terminal deoxynucleotidyl transferase [TdT] end-labeling ['TUNEL Assay'; Apop Tag, OncorPeroxidase kit]) was performed as a single- or two-color analysis as described previously (Krajewski et al, 1995), using the colorimetric substrates DAB and either VIP or SG (Vector Labs., Inc) for TUNEL and $\mathrm{Bcl}-2$ family proteins, respectively.

\section{Acknowledgements}

We thank Heying Zha for skilful histological preparation and Sabine Lensing-Höhn for immunocytochemical work, and T. Potter for manuscript editing. This manuscript was supported by a grant of the NIH (JCR, CA60181).

\section{References}

Cam Y, Neumann MR, Oliver L, Raulais D, Janet T and Ruch JV (1992) Immunolocalization of acidic and basic fibroblast growth factors during mouse odontogenesis [published erratum appears in Int J Dev Biol 1992 Dec; 36(4): following 599]. Int J Dev Biol 36: $381-389$

Casasco A, Calligaro A and Casasco M (1992) Proliferative and functional stages of rat ameloblast differentiation as revealed by combined immunocytochemistry against enamel matrix proteins and bromodeoxyuridine. Cell Tissue Res 270: $415-423$

Joseph BK, Savage NW, Young WG and Waters MJ (1994) Insulin-like growth factor-I receptor in the cell biology of the ameloblast: an immunohistochemical study on the rat incisor. Epithelial Cell Biol 3: 47-53

Krajewska M, Moss S, Krajewski S, Song K, Holt P and Reed JC (1996) Elevated expression of $\mathrm{Bcl}-\mathrm{X}$ and reduced Bak in primary colorectal adenocarcinomas. Cancer Res 56: 2422-2427

Krajewski S, Krajewska M and Reed JC (1996) Immunohistochemical analysis of in vivo patterns of Bak expression, a pro-apoptotic member of the Bcl-2 protein family. Cancer Res 56: 2849-2855

Krajewski S, Krajewska M, Shabaik A, Miyashita T, Wang H-G and Reed JC (1994a) Immunohistochemical determination of in vivo distribution of bax, a dominant inhibitor of bcl-2. Am J Pathol 145: 1323-1333

Krajewski S, Krajewska M, ShabaikA, Wang H-G, Irie S, Fong Land Reed JC (1994b) Immunohistochemical analysis of in vivo patterns of $\mathrm{Bcl}-\mathrm{X}$ expression. Cancer Res 54: $5501-5507$ 
Krajewski S, Mai JK, Krajewska M, Sikorska M, Mossakowski MJ and Reed JC (1995) Upregulation of bax protein levels in neurons following cerebral ischemia. $J$ Neurosci 15: 6364-6376

Lemus D, Romero S, Lemus R, Garcia J and Fuenzalida M (1996) Light microscopic detection of sugar residues in rabbit embryo teeth with lectin-horseradish peroxidase conjugates. J Morphol 227: 185-195

Mitsiadis TA, Couble P, Dicou E, Rudkin BB and Magloire H(1993) Patterns of nerve growth factor (NGF), proNGF, and p75 NGF receptor expression in the rat incisor: comparison with expression in the molar. Differentiation 54: 161-175

Mitsiadis TA, Dicou E, Joffre A and Magloire H (1992) Immunohistochemical localization of nerve growth factor (NGF) and NGF receptor (NGF-R) in the developing first molar tooth of the rat. Differentiation 49: 47-61

Mitsiadis TA and Luukko K (1995) Neutrotrophins in odontogenesis. Int J Dev Biol39: 195-202

Nishikawa S and Sasaki F (1995) DNA localization in nuclear fragments of apoptotic ameloblasts using anti-DNA immunoelectron microscopy: programmed cell death of ameloblasts. Histochem Cell Biol 104: 151 - 159

Saunders JW Jr (1996) Death in embryonic systems. Science 154: 604-612

Saxen L and Thesleff I (1992) Epithelial-mesenchymal interactions in murine organogenesis. Ciba Found Symp 165: 183-193; discussion 193-188
Sicher H and Bhaskar SN (1972) Orban's Oral Histology and Embryology. Mosby Company: St Louis, pp. 28-30

Thesleff I (1995a) Homeobox genes and growth factors in regulation of craniofacial and tooth morphogenesis. Acta Odontol Scand 53: 129-134

Thesleff I, Partanen AM and Vainio S (1991) Epithelial-mesenchymal interactions in tooth morphogenesis: the roles of extracellualr matrix, growth factors, and cell surface receptors. J Craniofac Genet Dev Biol 11: 229-237

Thesleff I, Vaahtokari A, Kettunen P and Aberg T (1995b) Epithelial-mesenchymal signaling during tooth development. Connect Tissue Res 32: 9-15

Thesleff I, Vaahtokari A and Partanen AM (1995c) Regulation of organogenesis. Common molecular mechanisms regulating the development of teeth and other organs. Int J Dev Biol 39: 35-50

Tureckova J, Sahlberg C, Aberg T, Ruch JV, Thesleff I and Peterkova R (1995) Comparison of expression of the msx-1, msx-2, BMP-2 and BMP-4 genes in the mouse upper diastemal and molar tooth primordia. Int J Dev Biol 39: 459-468

Vaahtokari A, Aberg T, Jernvall J, Keranen S and Thesless I (1996a) The enamel knot as a signaling center in the developing mouse tooth. Mech Develop 54: 39-43

Vaahtokari A, Aberg T and Thesless I (1996b) Apoptosis in the developing tooth: association with an embryonic signaling center and suppression by EGF and FGF-4. Development 122: 121-129 